\title{
Delirium following fesoterodine treatment for urgency incontinence in an 89-year old man
}

\author{
Jeannie Medeiros Charbonneau, PharmD;1 Rania Bisset, Pharm D; \\ Patrick Viet-Quoc Nguyen, BPharm, MSc ${ }^{1,2}$
}

'Centre Hospitalier de l'Université de Montréal (CHUM), Montreal, QC, Canada; ${ }^{2}$ HUM Research Centre, Montreal, QC, Canada

Cite as: Can Urol Assoc J 2016;10(7-8):E261-3. http://dx.doi.org/10.5489/cuai.3697

Published online July 12, 2016

\section{Abstract}

We describe the case of an 89-year-old man who developed delirium following the introduction of fesoterodine to treat his urgency incontinence. The patient started experiencing visual hallucinations approximately five days after starting fesoterodine $4 \mathrm{mg}$ once daily. Delirium resolved after fesoterodine was stopped. Despite the apparent safe cognitive profile due to its pharmacodynamic properties, fesoterodine should be used with caution in the elderly, frail population.

\section{Introduction}

Urgency incontinence affects up to $30 \%$ of the elderly population. ${ }^{1}$ Antimuscarinic agents used to treat urgency incontinence may cause central nervous system (CNS) effects, such as delirium and cognitive decline. ${ }^{2}$ Fesoterodine has a comparable efficacy to other antimuscarinic agents in urgency incontinence. ${ }^{2}$ Fesoterodine is rapidly metabolized into its active metabolite 5-hydroxymethyl tolterodine (5-HMT). 5 -HMT crosses the blood-brain barrier (BBB), but is actively transported out of the CNS by the P-glycoprotein (P-gp), which leads to a non-significant concentration in the CNS in an vivo animal model. ${ }^{3}$ From the data available from clinical trials, ${ }^{4,5}$ some authors have stated that fesoterodine doesn't cause cognitive impairment in elderly patients. Its effect on attention, memory, and executive function was similar to placebo in a double-blind, double-dummy, crossover study on 20 healthy elderly patients aged between 65 and 84 years old. ${ }^{6}$ In a double-blind clinical trial involving 562 vulnerable elderly patients, no deterioration of mini-mental state examination (MMSE) score was observed; however, two subjects reported subjective impairment after an increase to fesoterodine $8 \mathrm{mg}$ dose. $^{7}$ In another trial, three patients discontinued treatment due to an acute confusional state, but the site investigator judged it unrelated to fesoterodine. ${ }^{8}$ Cognitive decline was measured using memory tests (such as MMSE), which aren't as sensible for the detection of delirium as the confusion assessment method or the delirium rating scale. ${ }^{9,10}$ To our knowledge, delirium hasn't been formally observed with fesoterodine in the literature using deliriumspecific scales. This is, therefore, the first report on delirium related to fesoterodine.

\section{Case report}

An 89-year-old man with a history of hypertension, dyslipidemia, coronary artery disease, chronic obstructive pulmonary disease, gout, stage 4 chronic kidney disease (creatinine clearance $17 \mathrm{ml} / \mathrm{min}$ ), venous insufficiency with lower limb edema, liver metastases from colon neoplasia and prostate neoplasia with partial prostatectomy, and no prior history of cognitive impairment was admitted to the emergency of the Centre Hospitalier de I'Université de Montréal (CHUM) after experiencing visual hallucinations. The patient saw 50 people in his apartment and had gone to his neighbour's house to hide. After medical evaluation, he was admitted to the CHUM's geriatric ward with a diagnosis of delirium.

A complete blood work was done. Kidney function was stable according to baseline creatinine and hepatic function tests were normal. Computed tomography (CT) scan was similar to previous results. No neurological impairment, nor head trauma was reported. There were no signs of infection and metabolic markers, such as electrolytes, glycemia, and thyroid-stimulating hormone, were normal. According to his chart, the only recent change to his medication was the addition of fesoterodine at a dosage of $4 \mathrm{mg}$ once daily started five days prior to the hallucination report. His other prior medications included finasteride $5 \mathrm{mg}$ daily, amlodipine 5 mg daily, atorvastatin $20 \mathrm{mg}$ daily, metoprolol $50 \mathrm{mg}$ twice daily, furosemide $20 \mathrm{mg}$ daily, bicalutamide $50 \mathrm{mg}$ daily, and acetaminophen $650 \mathrm{mg}$ as needed. 
Fesoterodine was discontinued upon admission because it was suspected to be the cause of his delirium, but hallucination persisted for seven days. For the symptoms of delirium, risperidone $0.25 \mathrm{mg}$ once daily was prescribed and increased two days later to $0.25 \mathrm{mg}$ twice daily. Haloperidol was prescribed on an as-needed basis for agitation. Lorazepam $1 \mathrm{mg}$ subcutaneously was administered once because haloperidol was ineffective. All risperidone and haloperidol were discontinued 14 days later, as the patient improved clinically.

\section{Discussion}

Delirium is an acute decline in cognitive function, including disorganized thinking, inattention, and altered consciousness and mental status. ${ }^{11}$ It has been associated with increased hospital stay, mortality, and long-term decrease in functionality. ${ }^{9,12}$ Antimuscarinic agent are known to cause delirium. ${ }^{11}$ Stuhec reported a case of solifenacin-induced delirium that improved once it was stopped..$^{13}$ In a prospective cohort study of 14526 participants (mean age 62.7 years), Layton et al reported a significant association between tolterodine and visual hallucination. ${ }^{14}$ Other cases were reported with anticholinergics used in younger and older patients. ${ }^{15-17}$

In this case, hallucinations stopped seven days after stopping fesoterodine. As the half-life for 5-HMT is approximately eight hours, complete elimination would be expected after $40-56$ hours (5-7 half-life). ${ }^{18}$ Even if it was used at the correct dosage, fesoterodine is mainly eliminated by renal excretion and the patient's stage 4 chronic kidney disease could have slowed its elimination, explaining the lengthened duration of hallucinations. ${ }^{18}$ Indeed, a study by Malhotra et al showed a two-fold increase in Cmax and 2.3-fold increase in area under the curve (AUC) of 5-HMT in patients with severe renal impairment (creatinine clearance $<30 \mathrm{ml} / \mathrm{min}$ ). ${ }^{19}$

5 -HMT is inactivated by CYP 3 A4 and CYP 2D6. ${ }^{18}$ The patient used finasteride, amlodipine, atorvastatin, and bicalutamide, which are CYP $3 \mathrm{~A} 4$ inhibitors and substrate, and metoprolol, a CYP 2D6 substrate and minor inhibitor. Despite a theoretical risk of interaction with fesoterodine, none was documented in literature..$^{20,21}$

Diuretics may cause dehydration and hyponatremia leading to delirium. ${ }^{22}$ Furosemide also has an anticholinergic load. ${ }^{23}$ The patient was taking furosemide for over three years with no recent dose change. No signs of dehydration and normal electrolytes suggest that furosemide contribution to delirium was unlikely.

Delirium was treated by reversing the pharmacological cause and managing the symptoms with antipsychotics, which is appropriate according to current North American recommendations. ${ }^{24,25}$ However, the use of benzodiazepine for agitation could have contributed to the exacerbation of the delirium.
The adverse effect in our case report was evaluated using the Naranjo adverse drug reaction probability scale and was possibly associated with fesoterodine use (4 points). ${ }^{26}$

Until now, fesoterodine was known for its safe cognitive profile. The current case report raises the question whether 5-HMT can actually be in a sufficient concentration in the CNS to cause adverse reactions such as delirium in old, frail patients. The current patient is older and frailer than those included in the Kay's study. ${ }^{6}$ Therefore, until further research can be done, fesoterodine should be used with caution in those who might have a risk of increased drug exposure (such as renal impairment) or in those with a diminished cognitive reserve, notably the elderly and frail population.

Competing interests: Mr. Nguyen has received speaker and consulting fees from Astellas. The remaining authors declare no competing personal or financial interests.

Acknowledgement: The authors would like to thank Louise Mallet, BScPharm, PharmD, CGP, FESCP, for her assistance.

This paper has been peer-reviewed.

\section{References}

1. Dmochowski RR, Blaivas JM, Gormley EA, et al. Update of AUA guideline on the surgical management of female stress urinary incontinence. J Urol 2010;183:1906-14. http://dx.doi.org/10.1016/i. juro.2010.02.2369

2. Bettez M, Tule M, Carlson K, et al. 2012 update: Guidelines for adult urinary incontinence collaborative consensus document for the Canadian Urological Association. Can Urol Assoc J 2012;6:354-63. http: // dx.doi.org/10.5489/cuaj.12248

3. Callegari E, Malhotra B, Bungay PJ, et al. A comprehensive non-clinical evaluation of the CNS penetration potential of antimuscarinic agents for the treatment of overactive bladder. Br I Clin Pharmacol 2011;72:235-46. http://dx.doi.org/10.1111/i.1365-2125.2011.03961.x

4. Chapple C, Oelke M, Kaplan SA, et al. Fesoterodine clinical efficacy and safety for the treatment of overactive bladder in relation to patient profiles: A systematic review. Curr Med Res Opin 2015;31:1201-43. http://dx.doi.org/10.1185/03007995.2015.1032917

5. Mock S, Dmochowski RR. Evaluation of fesoterodine fumarate for the treatment of an overactive bladder. Expert Opin Drug Metab Toxicol 2013;9:1659-66. http://dx.doi.org/10.1517/17425255.20 13.858118

6. Kay GG, Maruff P, Scholfield D, et al. Evaluation of cognitive function in healthy older subjects treated with fesoterodine. Postgrad Med 2012;124:7-15. http://dx.doi.org/10.3810/pgm.2012.05.2543

7. Dubeau CE, Kraus SR, Griebling TL, et al. Effect of fesoterodine in vulnerable elderly subjects with urgency incontinence: A double-blind, placebo controlled trial. J Urol 2014;191:395-404. http://dx.doi. org/10.1016/i.juro.2013.08.027

8. Wagg A, Khullar V, Marschall-Kehrel D, et al. Flexible-dose fesoterodine in elderly adults with overactive bladder: Results of the randomized, double-blind, placebo-controlled study of fesoterodine in an aging population trial. J Am Geriatr Soc 2013;61:185-93. http://dx.doi.org/10.1111/igs.12088

9. Inouye $\mathrm{SK}$, van Dyck $\mathrm{CH}$, Alessi $\mathrm{CA}$, et al Clarifying confusion: The confusion assessment method. A new method for detection of delirium. Ann Intern Med 1990;113:941-8. hittp://dx.doi.org/10.7326/00034819-113-12-941

10. Trzepacz PT, Mittal D, Torres R, et al. Validation of the Delirium Rating Scale-revised-98: Comparison with the delirium rating scale and the cognitive test for delirium. J Neuropsychiatry Clin Neurosci 2001;13:22942. http://dx.doi.org/10.1176/inp.13.2.229

11. Inouye SK, Westendorp RG, Saczynski IS. Delirium in elderly people. Lancet 2014;383:911-22. http:// dx.doi.org/10.1016/S0140-6736(13)60688-1 
12. Wei LA, Fearing MA, Sternberg EJ, et al. The confusion assessment method: A systematic review of current usage. J Am Geriatr Soc 2008;56:823-30. http://dx.doi.org/10.1111/j.1532-5415.2008.01674.x

13. Stuhec M. Solifenacin-induced delirium and hallucinations. Gen Hosp Psychiatry 2013;35:682e3-4.

14. Layton D, Pearce GL, Shakir SA. Safety profile of tolterodine as used in general practice in England: Results of prescription-event monitoring. Drug Saf 2001;24:703-13. http://dx.doi.org/10.2165/00002018200124090-00005

15. Gotz AK, Reinhold SW, Szecsey A, et al. Severe anticholinergic drug-induced delirium in a young adult after renal transplantation. Transpl Int 2009;22:249-50. http://dx.doi.org/10.1111/j.14322277.2008.00759.x

16. Gulsun M, Pinar M, Sabanci U. Psychotic disorder induced by oxybutynin: Presentation of two cases. Clin Drug Investig 2006;26:603-6. http://dx.doi.org/10.2165/00044011-200626100-00007

17. Donnellan CA, Fook L, MCDonald P, et al. Oxybutynin and cognitive dysfunction. BMJ 1997;315:1363-4. http://dx.doi.org/10.1136/bmi.315.7119.1363

18. Malhotra B, Guan Z, Wood N, et al. Pharmacokinetic profile of fesoterodine. Int I Clin Pharmacol Ther 2008; 46:556-63. http://dx.doi.org/10.5414/CPP46556

19. Malhotra B, Gandelman K, Sachse R, et al. Assessment of the effects of renal impairment on the pharmacokinetic profile of fesoterodine. J Clin Pharmacol 2009;49:477-82. http://dx.doi. org/10.1177/0091270009332434

20. Baxter K, Stockley IH. Stockley's drug interactions: A source book of interactions, their mechanisms, clinical importance, and management. 8th ed. London; Chicago: Pharmaceutical Press; 2008.
21. American Pharmaceutical Association. Geriatric dosage handbook. 2014-2015: Clinical reference library 20th ed. Hudson, Ohio: Lexi-Comp; 2015:v.

22. Ruedinger JM, Nickel CH, Maile $S$, et al. Diuretic use, RAAS blockade and morbidity in elderly patients presenting to the emergency department with non-specific complaints. Swiss Med Wkly 2012;142:w13568. http://dx.doi.org/10.4414/smw.2012.13568

23. Carnahan RM, Lund BC, Perry PJ, et al. The Anticholinergic Drug Scale as a measure of drug-related anticholinergic burden: Associations with serum anticholinergic activity. J Clin Pharmacol 2006;46:1481-6. http://dx.doi.org/10.1177/0091270006292126

24. Devlin JW, Al-Qadhee NS, Skrobik Y. Pharmacologic prevention and treatment of delirium in critically ill and non-critically ill hospitalised patients: A review of data from prospective, randomized studies. Best Pract Res Clin Anaesthesiol 2012;26:289-309. http://dx.doi.org/10.1016/i.bpa.2012.07.005

25. Fong TG, Tulebaev SR, Inouye SK. Delirium in elderly adults: Diagnosis, prevention and treatment. Nat Rev Neurol 2009;5:210-20. http://dx.doi.org/10.1038/nrneurol.2009.24

26. Naranio $\mathrm{CA}$, Busto $\mathrm{U}$, Sellers $\mathrm{EM}$, et al. A method for estimating the probability of adverse drug reactions. Clin Pharmacol Ther 1981;30:239-45. http://dx.doi.org/10.1038/clpt.1981.154

Correspondence: Mr. Patrick Viet-Quoc Nguyen, CHUM Research Centre, Montreal, QC, Canada; patrick.nguyen@umontreal.ca 